\title{
Involvement of the Arcuate Nucleus of the Hypothalamus in Interleukin-1-Induced Anorexia
}

\author{
Teresa M. Reyes and Paul E. Sawchenko \\ Laboratory of Neuronal Structure and Function, The Salk Institute for Biological Studies and Foundation for Medical \\ Research, La Jolla, California 92037
}

\begin{abstract}
Cytokine-mediated anorexia is a component of "sickness behavior" and presents a significant obstacle in the treatment of chronic illnesses. We hypothesized an involvement of the hypothalamic arcuate nucleus (ARH) in mediating the anorexic effects of a systemic interleukin-1 (IL-1) challenge based on its content of peptidergic neurons involved in feeding, its expression of IL-1 receptors and its sensitivity to systemic IL-1. IL-1 (6 $\mu \mathrm{g} / \mathrm{kg}$, i.v.) was found to induce Fos expression in both proopiomelanocortin- and neuropeptide Y-expressing neurons in and around the ARH. Contrary to expectations, rats that had sustained lesions of the arcuate nucleus, produced by neonatal monosodium glutamate treatment, displayed a more pronounced suppression (by $25 \%$ ) of food intake than nonlesioned controls when treated with IL-1 after a $20 \mathrm{hr}$ fast. To confirm and
\end{abstract}

further characterize this unexpected result, a second ablation method was used in a similar paradigm. Animals bearing knife cuts designed to sever major ARH projections displayed an even more accentuated loss of appetite (by $60 \%$, relative to controls) in response to systemic IL-1. This effect exhibited at least some degree of specificity, because the knife cuts did not alter either IL-1 effects on another centrally mediated acute phase response (fever) or the anorexia produced by an alternate agent, fenfluramine. These results fail to support the hypothesized $\mathrm{ARH}$ mediation of IL-1-induced anorexia and may suggest rather that the net output of this cell group may serve normally to restrain cytokine-induced reductions in food intake.

Key words: anorexia; arcuate nucleus; interleukin-1; neuropeptide $Y$; proopiomelanocortin; sickness behavior
When humans or animals sustain an infection or severe tissue trauma, the immune system is activated as a primary line of defense. Activated leukocytes are recruited to the afflicted site or sites and release cytokines into the circulation. These proteins modulate the immune response by recruiting or blocking the actions of other immune cells. Additionally, cytokines mediate a "second line of defense" by acting on the CNS to coordinate a constellation of responses, sometimes referred to as "sickness behavior" (Hart, 1988). Such responses, which include anorexia, fever, somnolence, and lethargy, are adaptive in the near term (Hart, 1990), although they may become injurious if repeated or sustained. Furthermore, potentially beneficial immunotherapies involving long-term cytokine administration have proven impractical because of these very CNS side effects (Smith et al., 1990). The goal of the present studies was to achieve a better understanding of the neural substrates underlying one of these behaviors, specifically cytokine-mediated anorexia.

The proinflammatory cytokine interleukin-1 (IL-1) is rapidly released in response to infection or inflammation and can elicit a wide range of acute phase responses, including sickness behaviors, when given exogenously (Kent et al., 1996; Dantzer, 2001). Either systemic or central administration of IL-1 induces anorexia, ostensibly by way of actions exerted within the brain.

\footnotetext{
Received Jan. 7, 2002; revised March 19, 2002; accepted April 2, 2002.

This research was supported by National Institutes of Health Grant NS-21182 and was conducted in part by the Foundation for Medical Research. P.E.S. is an investigator of the Foundation for Medical Research. T.M.R. is the recipient of National Research Service Award support (DK-10135). We thank Carlos Arias and Kris Trulock for excellent technical and photographic expertise, respectively.

Correspondence should be addressed to Dr. Paul E. Sawchenko, Laboratory of Neuronal Structure and Function, The Salk Institute, 10010 North Torrey Pines Road, La Jolla, CA 92037. E-mail: sawchenko@salk.edu.

Copyright (C) 2002 Society for Neuroscience $0270-6474 / 02 / 225105-09 \$ 15.00 / 0$
}

Intracerebroventricular administration of an IL-1 receptor antagonist attenuates the appetite-reducing effects of systemic cytokine injection (Kent et al., 1992), suggesting either that IL-1 stimulates its own production within the brain or that circulating IL-1 may access the brain parenchyma. IL-1, a large hydrophilic protein, is unlikely to cross the blood-brain barrier (BBB) in biologically significant concentrations. However, numerous pathways have been hypothesized to explain how cytokines in the periphery come to influence CNS functioning, including (1) transduction by peripheral nerves (i.e., the vagus nerve; Watkins et al., 1995; Bluthe et al., 1996), (2) mechanisms involving the BBB, either via induction of local signaling molecules (e.g., nitric oxide, prostaglandins) by cells associated with the cerebral microvasculature (Van Dam et al., 1996) or through active transport across the barrier (Banks and Kastin, 1991), or (3) direct actions on circumventricular structures of the brain that lay outside the BBB (Blatteis, 1992).

Several lines of evidence point toward the arcuate nucleus of the hypothalamus $(\mathrm{ARH})$ as playing a role in IL-1-induced anorexia. The ARH is one of the few cell groups in rat brain where type I IL-1 receptors (IL-1R1) appear to be expressed by centrally projecting neurons (Ericsson et al., 1995), and it exhibits activational responses (Fos induction) to a systemic IL-1 challenge (Herkenham et al., 1998). In addition to several indirect means by which circulating IL-1 could influence ARH mechanisms, there is evidence to support the possibility that it might access them directly. The medial part of the ARH, where IL-1R1 is expressed, can bind certain peptides or proteins administered intravenously (van Houten et al., 1980, 1981), enjoys potential physical links (by way of broad perivascular spaces) with an adjoining circumventricular structure (median eminence), and displays a level of capillary permeability that substantially exceeds 
that of nearby parenchymal regions (Shaver et al., 1992). Moreover, the ARH houses peptidergic cell types implicated strongly in the stimulatory and inhibitory controls of food intake and energy balance (Elmquist et al., 1999; Kalra et al., 1999) and is interconnected extensively with other hypothalamic cell groups thought to be important in this regard (Broberger et al., 1998; Elias et al., 1998b). The present experiments were performed to test the hypothesis that the ARH mediates IL-1-induced anorexia.

Portions of these data have been presented in abstract form (Reyes and Sawchenko, 2000).

\section{MATERIALS AND METHODS}

Animals and surgical procedures. Adult male Sprague Dawley rats (250$300 \mathrm{gm}$ at the start of experimentation) were housed in a colony room on a $12 \mathrm{hr}$ light/dark cycle (lights on at 6:00 A.M.), with ad libitum access to food (Harlan Teklad rodent chow 8604) and water except where otherwise noted. Ambient room temperature was $23^{\circ} \mathrm{C}$. For intravenous administration of IL-1, animals were fitted with indwelling jugular venous catheters under ketamine-xylazine-acepromazine anesthesia. Catheters were filled with sterile heparinized saline, with the internal catheter placed at the atrium and exteriorized at an interscapular position. After surgery, animals were allowed to recover for $7 \mathrm{~d}$ before any experimentation, during which time they were handled daily. All procedures were approved by the Institutional Animal Care and Use Committee of the Salk Institute.

Cytokine administration. Recombinant rat interleukin- $1 \beta$, generously provided by Dr. Ron Hart (Rutgers University), was used in all experiments. The cytokine was stored at $-70^{\circ} \mathrm{C}$, and fresh aliquots were thawed before each experiment. The vehicle for IL- $1 \beta$ injection was $0.01 \%$ BSA, $0.01 \%$ ascorbic acid, $10 \mathrm{~mm}$ Tris- $\mathrm{HCl}$, and $36 \mathrm{~mm}$ sodium phosphate buffer, $\mathrm{pH}$ 7.4. Controls included the injection of vehicle as well as injection of heat-inactivated $\mathrm{IL}-1\left(70^{\circ} \mathrm{C}, 30 \mathrm{~min}\right)$, which inactivates the cytokine, but would not affect endotoxin (Majde, 1993). Animals given heat-inactivated IL-1 were indistinguishable from vehicle-injected animals, behaviorally and with respect to Fos induction.

Experimental procedures and analysis. To monitor induced patterns of Fos expression, rats were injected at 9:00 A.M. with IL-1 $\beta(6 \mu \mathrm{g} / \mathrm{kg})$ or vehicle, and perfused at a range of time points $(30,60,90,120,180$, and $240 \mathrm{~min}$ ). For behavioral experiments, IL-1 or vehicle was administered intravenously to animals at 8:00 A.M., after a $20 \mathrm{hr}$ fast. Deprivationinduced refeeding was used in these studies to be able to anticipate the onset of feeding, a consideration that is particularly important in view of the relatively mild IL-1 challenge conditions we used. At 8:30 A.M., food was presented to the animals, and food intake was measured manually to the nearest $0.1 \mathrm{gm}$ every hour for $4 \mathrm{hr}$, and at $6,8,12$, and $24 \mathrm{hr}$. Data were analyzed using ANOVA, with the Bonferonni correction for multiple comparisons applied as warranted.

ARH lesions and knife cuts. Late-term pregnant female rats were allowed to deliver normally, and litter sizes were culled to 8-10 pups. To produce ARH lesions, pups were injected with monosodium glutamate (4 $\mathrm{mg} / \mathrm{gm}$, i.p.; Sigma, St. Louis, MO) or saline every other day for the first 10 days postnatally (Meister et al., 1989). At 3 weeks of age, animals were separated from the mother and segregated on the basis of treatment status (lesion versus control). At 8 weeks, animals were implanted with a jugular catheter as described. A within-subjects design was used in which all animals received both saline and IL-1 injections, spaced 1 week apart, with the order counterbalanced across conditions. A subset of animals (five lesioned, two control) continued to have patent catheters 1 week after completion of the behavioral experiments. These animals were given a second injection of IL-1 (6 $\mu \mathrm{g} / \mathrm{kg})$ and killed $3 \mathrm{hr}$ later to examine patterns of Fos expression. A separate group of adult animals were administered knife cuts designed to sever principal (vertically directed) projections of the ARH. Cuts were produced in the horizontal plane by first lowering an $\mathrm{L}$-shaped wire knife on the midline $(-1.7 \mathrm{~mm}$ from Bregma), with the 1-mm-long cutting arm directed caudally, to a depth of $7.5 \mathrm{~mm}$. The knife was rotated $360^{\circ}$ and then removed. At this time, animals were also implanted intra-abdominally with a telemeter (Minimitter, Bend, OR) for remote monitoring of body temperature and activity. Receivers placed beneath the cage collected body temperature data and monitored gross horizontal movement. Animals were allowed to recover for 2 weeks, at which time intravenous catheters were implanted. One week later, animals received the first of two injections.
Again, this study used a within-subjects design, with each animal receiving both saline and IL-1 treatment, 1 week apart, in counterbalanced order. One week after the second injection, a subset of animals (six knife cut, four controls) were challenged with an intraperitoneal injection of fenfluramine $(2 \mathrm{mg} / \mathrm{kg})$, and their food intake monitored as above.

Tissue processing and histology. Animals were deeply anesthetized with chloral hydrate $(350 \mathrm{mg} / \mathrm{kg}$, i.p.) and perfused via the ascending aorta with saline followed by ice-cold $4 \%$ paraformaldehyde in $0.1 \%$ borate buffer at $\mathrm{pH}$ 9.5. Brains were postfixed for $16 \mathrm{hr}$ and cryoprotected overnight in $10 \%$ sucrose in $0.1 \mathrm{~m}$ phosphate buffer. Six series of $30-\mu \mathrm{m}-$ thick frozen sections were cut using a sliding microtome, collected in cold ethylene glycol-based cryoprotectant, and stored at $-20^{\circ} \mathrm{C}$ until histochemical processing.

Hybridization histochemistry. In situ hybridization was performed using ${ }^{35}$ S-labeled sense and antisense (control) cRNA probes labeled to similar specific activities. The neuropeptide Y (NPY) probe detected a $287 \mathrm{bp}$ segment of exon 2 (Larhammar et al., 1987), whereas the proopiomelanocortin (POMC) probe detected a $500 \mathrm{bp}$ segment from the middle of the N-terminal portion of the peptide to the poly(A) tail (Chen et al., 1983). Slides were digested with $0.1-10 \mu \mathrm{g} / \mathrm{ml}$ proteinase $\mathrm{K}$ for 30 $\mathrm{min}$ at $37^{\circ} \mathrm{C}$. Probes were labeled to specific activities of $1-3 \times 10^{9}$ $\mathrm{dpm} / \mu \mathrm{g}$ and applied to the slide at concentrations of $\sim 10^{7} \mathrm{cpm} / \mathrm{ml}$, overnight at $56^{\circ} \mathrm{C}$ in a solution containing $50 \%$ formamide, $0.3 \mathrm{M} \mathrm{NaCl}$, $10 \mathrm{~mm}$ Tris, $1 \mathrm{~mm}$ EDTA, $0.05 \%$ tRNA, $10 \mathrm{~mm}$ dithiothreitol, $1 \times$ Denhardt's solution, and $10 \%$ dextran sulfate, after which they were treated with $20 \mu \mathrm{g} / \mathrm{ml}$ of ribonuclease A for $30 \mathrm{~min}$ at $37^{\circ} \mathrm{C}$ and washed in $15 \mathrm{~mm} \mathrm{NaCl} / 1.5 \mathrm{~mm}$ sodium citrate with $50 \%$ formamide at $70^{\circ} \mathrm{C}$. Slides were then dehydrated and exposed to x-ray films ( $\beta$-Max; Eastman Kodak, Rochester, NY) for $18 \mathrm{hr}$. They were coated with Kodak NTB-2 liquid emulsion and exposed at $4^{\circ} \mathrm{C}$ for $10-30 \mathrm{~d}$, as determined by the strength of signal on film. Slides were developed with Kodak D-19 and fixed with Kodak rapid fixer.

Immunohistochemistry. Primary antisera included a rabbit polyclonal antiserum directed against the N-terminal portion (amino acids 5-16) of a synthetic human Fos protein (used at 1:5000; Santa Cruz Biotechnology, Santa Cruz, CA). Specific staining was blocked by preincubation (overnight at $4^{\circ} \mathrm{C}$ ) with $30 \mu \mathrm{M}$ of the synthetic immunogen. Also used were rabbit-derived polyclonal antisera directed against human glial fibrillary acidic protein (GFAP; used at 1:2000; Chemicon, Temecula, $\mathrm{CA})$, and $\alpha$-melanocyte-stimulating hormone ( $\alpha$-MSH; used at 1:2000; Immunonuclear Corporation, Stillwater, MN). Endogenous peroxidase activity was neutralized by treating tissue for $10 \mathrm{~min}$ with $0.3 \%$ hydrogen peroxide, followed by $8 \mathrm{~min}$ in $1 \%$ sodium borohydride to reduce free aldehydes. Cells were permeabilized with PBS- $-2 \%$ Triton X-100 and then placed for $1 \mathrm{hr}$ in PBS-4\% normal blocking serum. Tissue was incubated with primary antibody at empirically determined concentrations for $48 \mathrm{hr}$ in PBS-2\% blocking serum. Localization was performed using a conventional avidin-biotin immunoperoxidase method or through the use of fluorochrome-conjugated antisera. For combined immuno- and hybridization histochemistry experiments, slight modifications to the protocol were required. Immunostaining was performed first with the following adjustments: (1) nonimmune (blocking) sera, potential sources of RNase contamination, were replaced with $2 \%$ BSA and $2 \%$ heparin sulfate, and (2) nickel enhancement steps were eliminated from the immunostaining protocol because the nickel-based reaction product does not survive the hybridization steps.

Quantification. Differences in the relative abundance of Fos were estimated by simple cell counting. Counts of stained neurons were made in regularly spaced series of sections in cell groups of interest defined on the basis of adjoining Nissl-stained sections.

\section{RESULTS}

\section{IL-1-induced anorexia}

Based on preliminary experiments, an intravenous dose of 6 $\mu \mathrm{g} / \mathrm{kg}$ recombinant rat IL $-1 \beta$ was found to provoke a reliable and moderately robust suppression of food intake after a $20 \mathrm{hr}$ fast. Repeated measures ANOVA revealed a significant interaction between drug and time $\left(F_{(1,5)}=3.40 ; p<0.02\right)$, with both main effects also reaching statistical significance. Animals administered IL- $1 \beta$ ate significantly less than vehicle-injected controls mainly during the first $2 \mathrm{hr}$ after injection, and secondarily during the latter phases of the monitoring period (12-24 hr) (Fig. 1). 

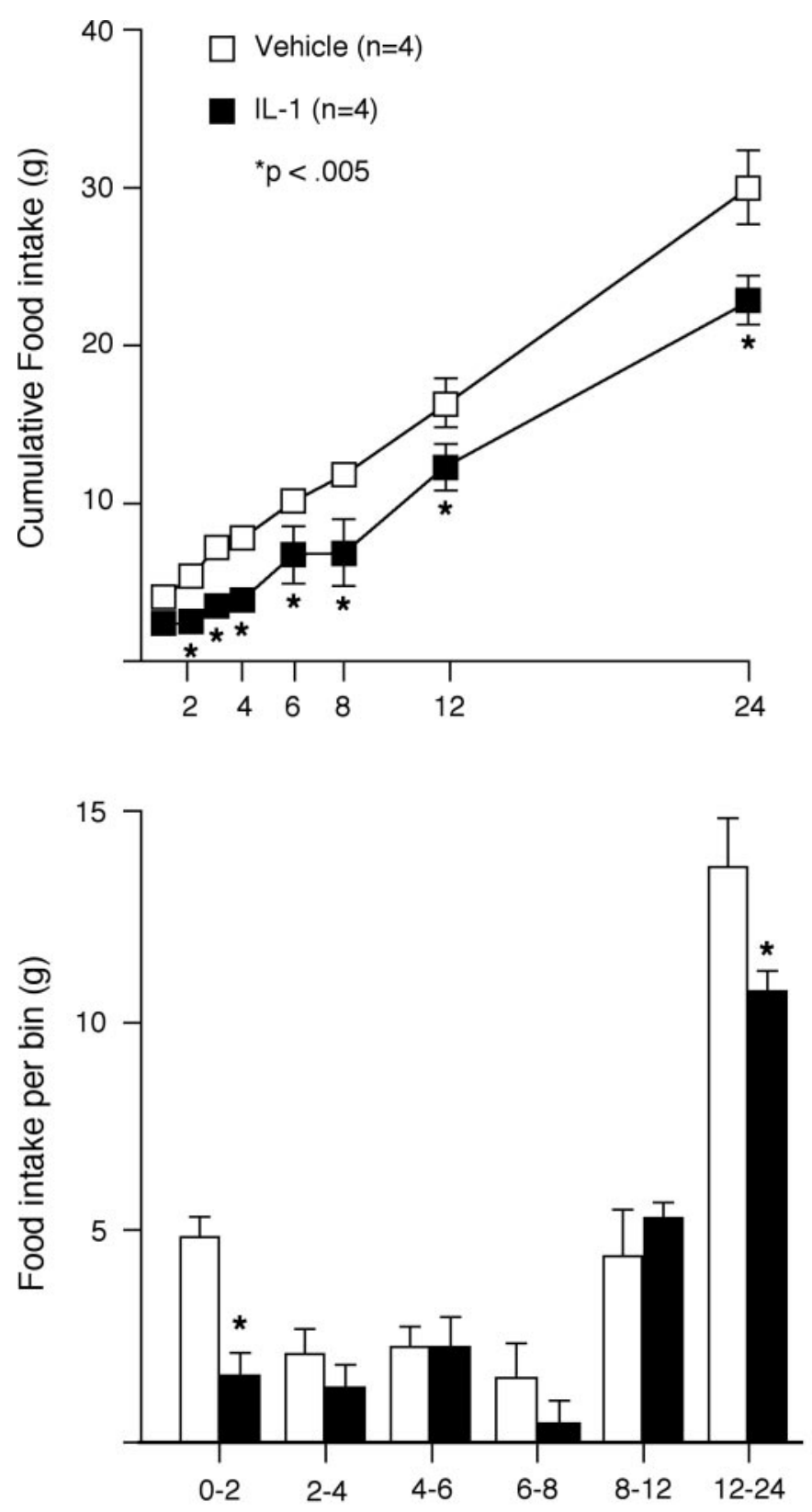

Hours Post-injection

Figure 1. IL-1 suppression of deprivation-induced feeding. Top, Mean \pm SEM cumulative food intake over $24 \mathrm{hr}$ after intravenous administration of IL-1 $\beta(6 \mu \mathrm{g} / \mathrm{kg})$ (open squares, vehicle; filled squares, IL-1-injected). Bottom, Food intake per time bin. IL-1-induced suppression of food intake was manifest primarily during the $2 \mathrm{hr}$ immediately after injection. $n=4$; *differs significantly from vehicle-treated values, $p<0.005$.

\section{IL-1-sensitive ARH neurons}

Immunohistochemical detection of Fos protein induction was used to identify and characterize ARH neurons that exhibited sensitivity to a behaviorally effective cytokine dose. Rats injected with $6 \mu \mathrm{g} / \mathrm{kg}$ rat IL- $1 \beta$ displayed an orderly progression of Fos induction in brain (peak at $\sim 1-2 \mathrm{hr}$ ), whose overall pattern was similar to that described previously (Ericsson et al., 1994). While not rivaling the strength of activational responses seen in such major sites of expression as the paraventricular, central amygda- loid, and lateral parabrachial nuclei, the nucleus of the solitary tract and ventrolateral medulla, a moderate number of Fospositive neurons ( $38 \pm 5$ cells per section, bilaterally) was distributed relatively uniformly throughout the ARH. Material from saline-injected controls contained no more than three or four labeled cells per section through the ARH, and the majority of sections contained none (Fig. 2).

Combined immuno- and hybridization histochemical methods were then used to determine the extent to which IL-1-sensitive ARH neurons might express key peptides implicated in the positive and negative control of food intake and energy balance. Activated neurons expressing the POMC transcript were evident at all time points investigated and relatively uniformly throughout the rostrocaudal extent of this nucleus (Fig. 2). Similarly, activated neurons expressing the NPY transcript were also evident at all time points and throughout the extent of the nucleus. A greater percentage of activated neurons expressed POMC mRNA (30 vs 23\%; $p<0.002$ ), and this pattern did not differ significantly across the time points examined. Outside the arcuate nucleus, activated cells expressing NPY mRNA were also evident in the anterior hypothalamic nucleus, where the vast majority of the scattered Fos-positive cells in this region were associated with positive hybridization signals for NPY mRNA.

\section{MSG lesion effects}

Because IL-1-sensitive ARH neurons expressed both orexigenic and anorexigenic neuropeptides, we evaluated the behavioral feeding response to IL-1 in animals bearing ARH lesions produced by neonatal MSG treatment. Consistent with previous reports on this preparation (Nemeroff et al., 1977), lesioned animals at the time of testing (10-12 weeks old) weighed slightly less, exhibited frankly stunted linear growth relative to control animals, and manifest an overt adiposity. Furthermore, examination of Nissl-stained series of sections from MSG-treated rats revealed that all lesioned animals displayed nearly complete optic nerve atrophy, as well as an enlarged third ventricle, and a profound, but not complete, cell loss in the ARH (Fig. 3). No obvious differences in cellularity were evident elsewhere in the brain, including circumventricular organs. POMC- and NPYexpressing neurons were dramatically reduced, but not fully eliminated, in MSG-treated rats. Whereas POMC-positive cells were virtually lacking from the arcuate nucleus of lesioned animals, the laterally contiguous POMC population that lies outside the borders of this cell group was ostensibly unaffected (Fig. 3). Similarly, although NPY mRNA signals were markedly attenuated in arcuate nuclei of lesioned animals, some sparing of the most medial contingent of cells exhibiting this phenotype was observed consistently (Fig. 3). Extra-arcuate expression of NPY mRNA (e.g., in isocortex and dorsomedial nucleus of the hypothalamus) was not affected by the lesion.

When tested as adults in a deprivation induced re-feeding paradigm, control animals responded to IL-1 with the expected acute suppression of food intake, consuming $64.6 \%$ of what they ate after a vehicle injection during the initial $4 \mathrm{hr}$ after injection (Fig. 4) (8.8 gm after saline injection vs 5.7 gm after IL-1). In contrast to expectation, however, lesioned animals responded to IL-1 with an even more pronounced reduction of food intake, eating only $48.8 \%$ of what they ate after a vehicle injection, a difference that was significantly $(25 \%)$ lower than the control animals at the $4 \mathrm{hr}$ post-injection time point $(p<0.05 ; 6.7 \mathrm{gm}$ after saline injection vs $3.3 \mathrm{gm}$ after IL-1). By $8 \mathrm{hr}$ after injection, 


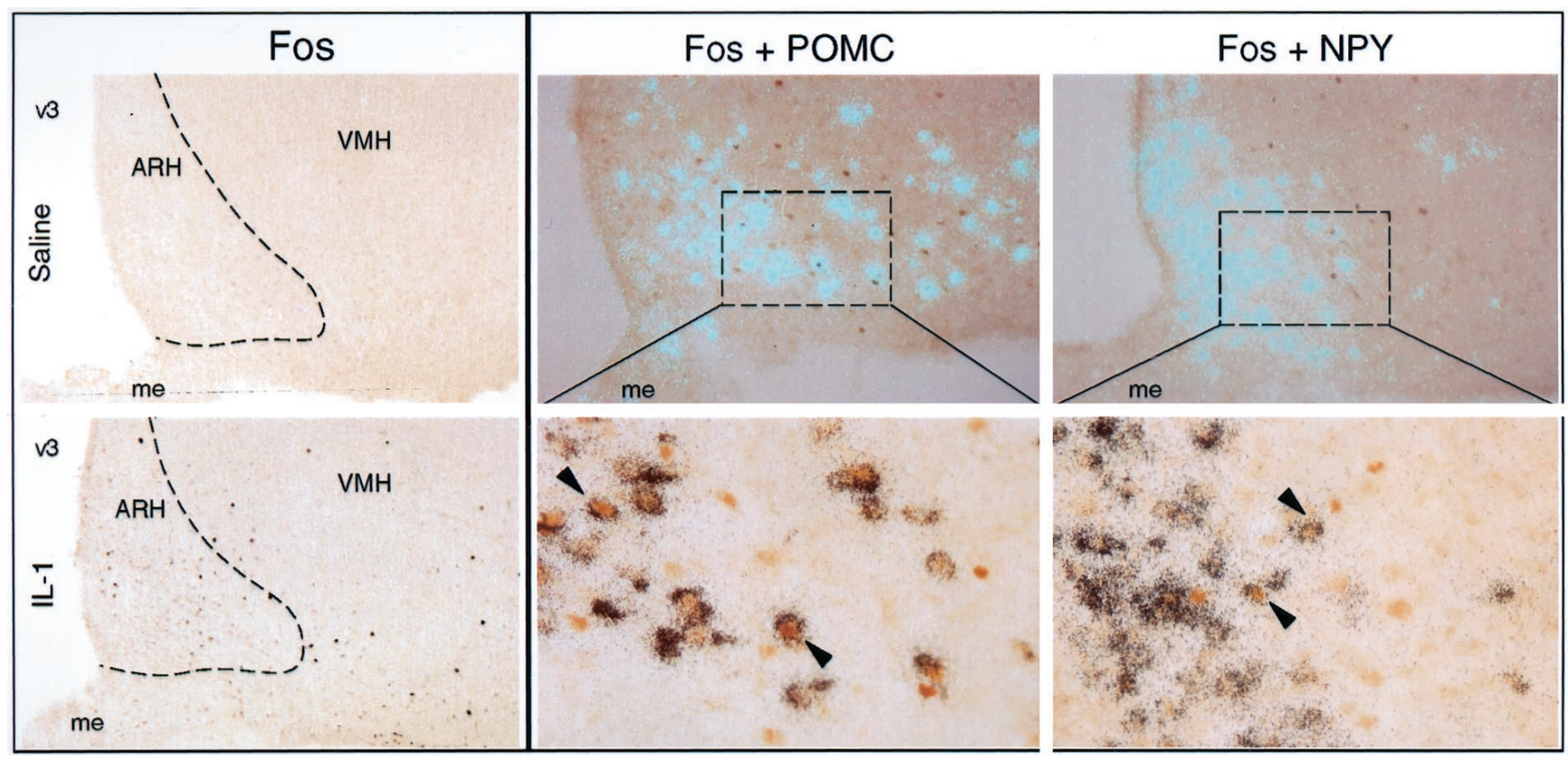

Figure 2. IL-1-induced Fos expression in the arcuate nucleus. Left, IL-1-induced Fos-IR (brown nuclei) was seen reliably in the arcuate nucleus and the POMC-rich region laterally adjoining it (bottom). Saline-injected animals (top) showed little to no Fos-IR in the arcuate. Both photomicrographs, 45×. Center and right, Chemical characterization of IL-1-responsive neurons of the ARH. Polarized epifluorescence (top) and higher magnification bright-field photomicrographs (bottom) of the ARH, showing dual localization of Fos-IR (brown nuclei) with POMC (center) or NPY (right) mRNAs (aqua or black grains). Substantial proportions of Fos-IR neurons displayed positive hybridization signals for each transcript (arrowheads), although cells labeled singly for either marker were also apparent. Doubly-labeled cells are seen throughout the longitudinal extent of the ARH but were most prominent rostrally. Rats were killed $3 \mathrm{hr}$ after intravenous injection of $6 \mu \mathrm{g} / \mathrm{kg}$ rat IL-1. Magnifications: top, 35×; bottom, 220×. AHA, Anterior hypothalamic area; fx, fornix; $m e$, median eminence; $m p(\mathrm{pm})$, medial parvocellular (posterior magnocellular) part of the paraventricular nucleus; $V M H$, ventromedial nucleus.

and thereafter, values from lesioned and control animals were indistinguishable from one another.

To gain insight into the manner in which MSG lesions may have affected the response to IL-1 of a potentially relevant downstream target of ARH projections, lesioned and control animals were administered another intravenous injection of IL-1 $3 \mathrm{hr}$ before killing, and Fos expression in the paraventricular nucleus of the hypothalamus (PVH) was evaluated. As noted above, IL-1 injection typically results in a robust activation of PVH neurons, and this activation was evident in nonlesioned control animals. Visual inspection indicated that lesioned animals exhibited a consistent, although somewhat variable, reduction in the number of Fos-IR neurons in the PVH (Fig. 5), so these were then counted and correlated with the amount of food eaten per time bin after an injection of IL-1. The number of Fos-IR neurons in the PVH was positively correlated with the amount of food eaten at $2 \mathrm{hr}\left(r^{2}=0.76 ; p<0.05\right.$, two-tailed test $)$. Thus, animals that displayed the most muted IL-1-stimulated Fos induction in the PVH (i.e., MSG-lesioned rats) tended reliably to conform to those that exhibited the most profound (i.e., most potentiated) suppression of food intake. This relationship was only statistically reliable at the $2 \mathrm{hr}$ time point.

\section{Knife cut effects}

Because MSG lesions led to overt physiological changes (i.e., adiposity), and their effect on cytokine-induced anorexia was relatively small and opposite in direction from what was expected, a second ablation method was tested in a similar paradigm. This involved placing knife cuts in the horizontal plane dorsal to the arcuate nucleus, designed to sever major, vertically directed, projections emanating from this cell group (Fig. 6). Others (Bell et al., 2000) have reported significant weight gain after similar lesions, although such an effect was not observed in our animals (2 week weight gain: controls 46 gm, knife cut 37 gm, NS.). The placement of the knife cuts was evaluated after behavioral testing in Nissl material and in sections stained for glial fibrillary acidic protein to define the extent of the glial scar. Their effectiveness was verified by the accumulation of immunoreactive $\alpha$-MSH in axons immediately proximal to the lesion site.

Deprivation-induced refeeding challenges were performed 14-21 d after knife cut or sham surgery. Values from shamoperated controls $(n=3)$ did not differ from those of an unoperated control group $(n=3)$, and the two groups were combined to increase statistical power. Compared with this pooled control group, knife cut animals demonstrated an even more pronounced potentiation of IL-1-induced anorexia than was observed in MSG-lesioned rats (Fig. 7). Two hours after an injection of IL-1, knife cut animals ate only $24 \%$ of what they ate after a vehicle injection (6.2 gm after saline injection vs $1.5 \mathrm{gm}$ after IL-1), compared with $59 \%$ in the controls $(4.5 \mathrm{gm}$ after saline injection vs 2.6 gm after IL-1), amounting to a $60 \%$ reduction $(p<0.05)$. As was the case with MSG-lesioned animals, significant betweengroup differences were not observed beyond $8 \mathrm{hr}$ after injection. To evaluate whether knife cuts might similarly affect the anorexia induced by other means, lesioned $(n=6)$ and control $(n=4)$ animals were also challenged with systemic fenfluramine $(2 \mathrm{mg}$ / $\mathrm{kg}$, i.p.). The two groups responded similarly to this challenge, demonstrating a modest suppression of food intake, evident primarily at $2 \mathrm{hr}$ after injection, when control animals exhibited a $68.5 \pm 23 \%$ suppression of food intake, as compared with a saline injection, whereas the lesioned group ate $60.4 \pm 15 \%$ less food. 

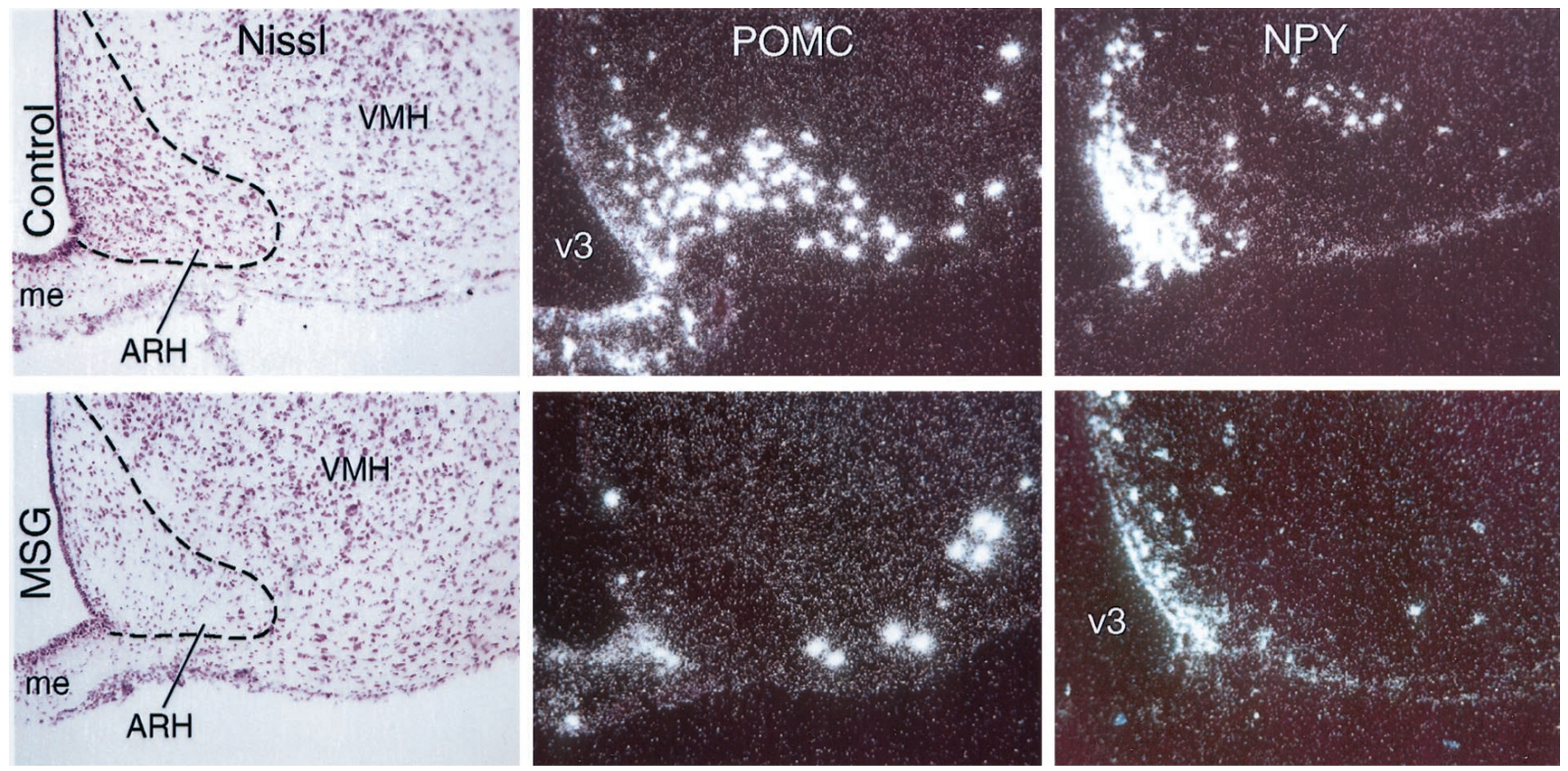

Figure 3. Evaluation of MSG lesions. Sections through the ARH of representative control (top) and MSG-lesioned (bottom) animals. Left, Examination of Nissl-stained material revealed substantial cell loss in the ARH of MSG-lesioned animals, with the most substantial sparing seen in the dorsomedial aspect of the nucleus. Middle, Dark-field photomicrographs showing POMC mRNA expression. MSG lesions virtually eliminated POMC cells from the ARH proper, although positively hybridized neurons lateral to the ARH were spared. Right, NPY mRNA expression in the ARH of lesioned animals was markedly attenuated, but not abolished, with sparing seen reliably in the ventromedial aspect of the nucleus. All photomicrographs, $50 \times$. me, Median eminence; $V M H$, ventromedial nucleus; $v 3$, third ventricle.

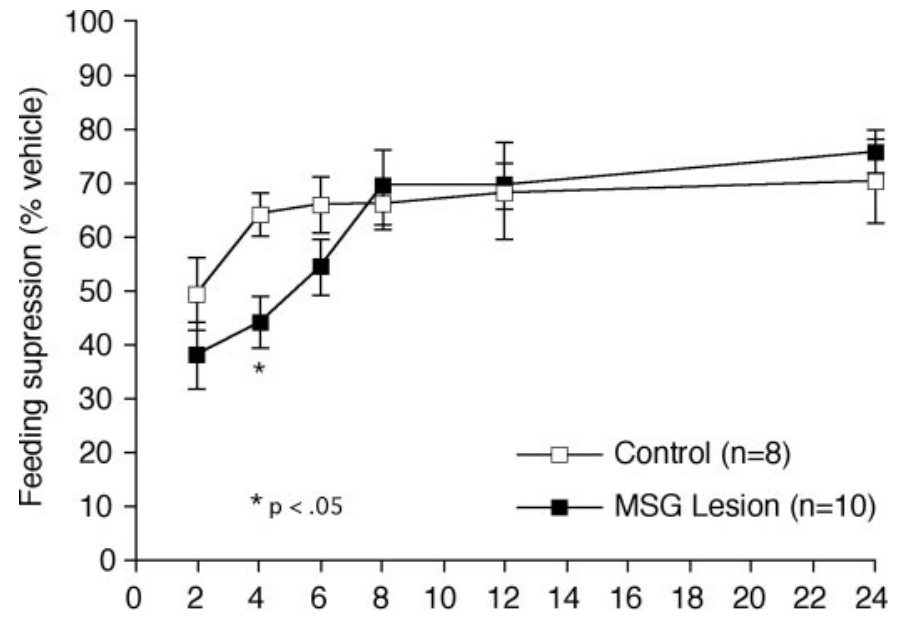

Hours Post-injection

Figure 4. Accentuation of IL-1-induced feeding suppression in MSGlesioned rats. Mean \pm SEM cumulative food intake of control (open squares) and MSG-lesioned rats (filled squares) after an injection of IL-1, expressed as percentage of each animal's own response to vehicle injection. MSG-lesioned animals $(n=10)$ displayed a significantly greater suppression of feeding at $4 \mathrm{hr}$ after injection compared with control animals $(n=8)$. Beyond $8 \mathrm{hr}$, lesioned animals' food intake did not differ reliably from control values. ${ }^{*}$ Differs significantly from vehicle-treated values, $p<0.05$.

At no time point did the two groups differ significantly, and both groups returned to near normal levels of food intake by $24 \mathrm{hr}$, at which time each had consumed $90 \%$ of what they ate after a saline injection.
To determine whether the knife cut effect was specific to this particular manifestation of sickness behavior, activity levels and core body temperature were monitored telemetrically in lesioned and sham-operated animals. Both groups evinced comparable acute increases in body temperature $\left(0.8-1.0^{\circ} \mathrm{C}\right.$ at $2-3 \mathrm{hr}$ after injection) in response to injection of IL-1, a well known pyrogen (Fig. 8). Although both groups also exhibited a tendency toward decreased activity during the $\sim 6 \mathrm{hr}$ immediately after an IL-1 challenge (average $25 \%$ reduction in activity levels), there was no reliable difference in activity levels at any time point.

\section{DISCUSSION}

Previous studies and present findings localizing IL-1 sensitivity to ARH populations implicated in the control of energy balance provided a basis for hypothesizing a role for this cell group in the mediation of cytokine-induced anorexia. The results of experiments using independent means of disrupting arcuate outputs failed to support this view, revealing instead an exaggeration of IL-1-induced feeding suppression in lesioned animals. The results support an involvement of the ARH in IL-1-induced anorexia, but not a mediating role. Instead, the net output of the nucleus appears normally to restrain the cytokine-induced reduction in food intake.

\section{IL-1-sensitive arcuate neurons}

The present study provides the first phenotypic characterization of IL-1-responsive ARH neurons, localizing Fos induction to both NPY- and POMC-expressing populations; activation of each was evident as early as $30 \mathrm{~min}$ after injection and persisted through at least $4 \mathrm{hr}$. Although these phenotypes accounted for a majority $(\sim 70 \%)$ of activated neurons in this cell group, it should be emphasized that these populations coexpress other neuroactive agents, including agouti-related protein (AgRP; with NPY; 

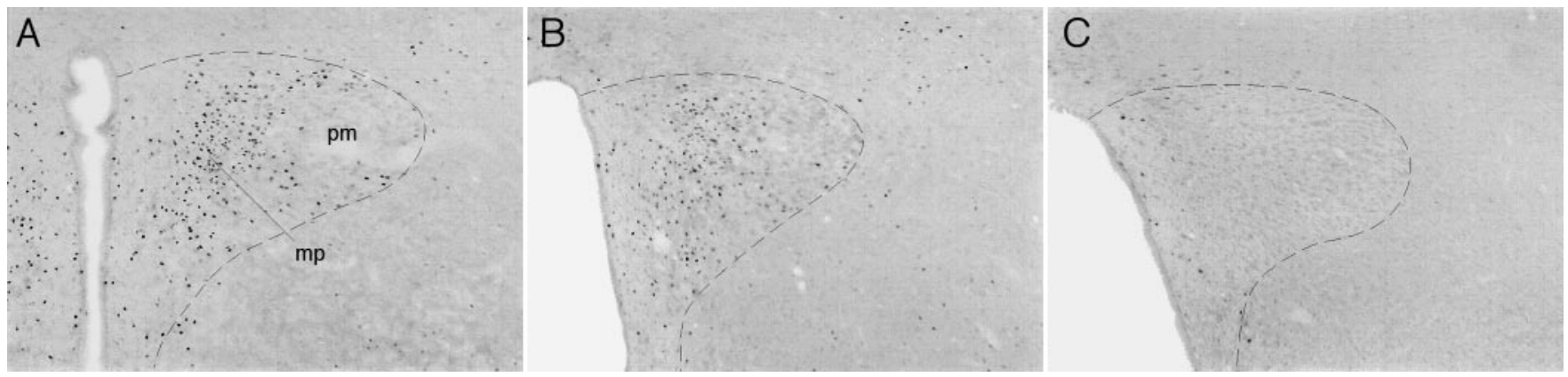

Figure 5. Reduction of IL-1-induced Fos expression in MSG-lesioned rats. Intravenous IL-1 induced robust Fos expression in the paraventricular nucleus in a representative control animal $(A)$, concentrated in the medial parvocellular region $(m p)$. Sections from two ARH-lesioned animals $(B$, $C)$ illustrate the reduced Fos expression seen in these animals, which ranged from an obvious attenuation $(B)$ to a nearly total elimination of the response $(C)$. Also apparent in the lesioned animals is the enlargement of the third ventricle that was characteristic of MSG-treated rats. Dashed line outlines the approximate border of the paraventricular nucleus. All photomicrographs, $60 \times . p m$, Posterior magnocellular part (paraventricular nucleus).

Broberger et al., 1998), and cocaine- and amphetamine-regulated transcript (CART; with POMC; Elias et al., 1998a), which may be relevant to the observed behavioral effects. Arcuate neurons issue extensive projections within the hypothalamus, prominently targeting the $\mathrm{PVH}$, as well as additional areas potentially involved in feeding and energy balance, such as the dorsomedial and ventromedial nuclei and the lateral hypothalamic area (Sawchenko, 1998). Additional studies using retrograde tracing methods will be required to identify downstream targets of IL-1-sensitive arcuate neurons.

\section{MSG lesions}

Neonatal monosodium glutamate treatment has been used extensively to generate arcuate nucleus lesions without involving local axons-of-passage. Our lesioned animals demonstrated a characteristic pattern of cell loss (Meister et al., 1989), which included a marked, although incomplete, destruction of POMC- and NPYexpressing cells. Additionally, potentially relevant cells displaying these phenotypes were found in hypothalamic areas unaffected by MSG treatment. These included an NPY population in the anterior hypothalamic area and POMC neurons lateral to the ARH proper, both of which displayed substantial IL-1 sensitivity. Extra-arcuate POMC neurons may project in a manner somewhat distinct from those within the nucleus, proper (Khachaturian et al., 1986), and have been suggested as being more important in the control of food intake than the medial contingent (Bergen et al., 1998). It remains to be determined what, if any, role either population may play in cytokine-induced anorexia. When tested as adults, MSG-lesioned animals demonstrated a mildly potentiated anorexia in response to IL-1, eating significantly less immediately after the challenge, with the effect persisting for somewhat longer than in controls. Although unexpected, and arguing against the hypothesized nature of ARH involvement in cytokine anorexia, this result is consistent with work describing exaggerated febrile and somnogenic responses to IL-1 (Martin et al., 1990; Opp et al., 1990), although it must be noted that in these studies the cytokine was administered centrally.

Also unexpected were MSG lesion effects on IL-1-induced activational responses in the PVH. Lesioned animals displayed substantial reductions in IL-1-induced Fos expression, whose magnitude was positively related to lesion effects on behavioral responses. While the significance of this relationship is unclear, it is interesting to note this positive correlation with food intake was observed only at the earliest time point $(2 \mathrm{hr})$, when cytokine effects on behavior are most pronounced (Fig. 1). This relation- ship was surprising in light of evidence implicating an alternate source of PVH afferents, medullary catecholamine neurons, in mediating IL-1-stimulated activational responses (Ericsson et al., 1994; Buller et al., 2001). The PVH houses multiple visceromotor cell types, including parvocellular neurosecretory neurons that express corticotropin-releasing factor for the control of pituitaryadrenal responses to stress (Sawchenko et al., 2000), and has been implicated as a site of action for multiple orexigenic and anorexigenic peptides (Abbott et al., 2001; C. Wang et al., 2001). It remains to be determined whether our findings may generalize to other indices (secretory, biosynthetic) of PVH function, and whether any role for arcuate nucleus afferents in such responses may be mediating or permissive.

\section{Disruption of arcuate projections}

Knife cuts were used as a second means of disrupting ARH outputs, to test the validity of conclusions suggested by the MSG lesion data. These fiber transections were placed dorsal to the ARH in the horizontal plane, intended to sever projections (including POMC- and NPY-containing ones) that course through the periventricular region toward the $\mathrm{PVH}$ and other targets (Baker and Herkenham, 1995). Projections that exit the nucleus laterally would presumably be spared. Such knife cuts reduced the $\alpha$-MSH and NPY inputs to the PVH, but did not eliminate them. Behaviorally, these animals also exhibited a potentiation of IL1-induced anorexia, manifest particularly during the first 1-2 hr after injection, which was substantially more robust than that seen in MSG-lesioned rats. This effect exhibited some specificity to food intake, because IL-1 effects on body temperature were comparable in knife cut and control animals and appeared specific to the nature of the challenge, because fenfluramine-induced anorexia was not reliably affected. Collectively, these data suggest that ablation of either arcuate neurons or their outputs results in accentuated IL-1 induced anorexia. A potential link between obesity and exaggerated cytokine responsiveness has been suggested, because genetically obese Zucker rats have been found to display exaggerated anorectic and febrile responses to centrally administered IL-1 (Plata-Salaman et al., 1997, 1998). This is unlikely to explain the present results, because only the MSGtreated animals manifested a significant adiposity, yet it was the knife cut group that showed the most marked behavioral potentiation. Furthermore, it is difficult to directly compare these studies because they differed in the route of cytokine administration, and in our paradigm, anorexia and fever did not respond similarly. 

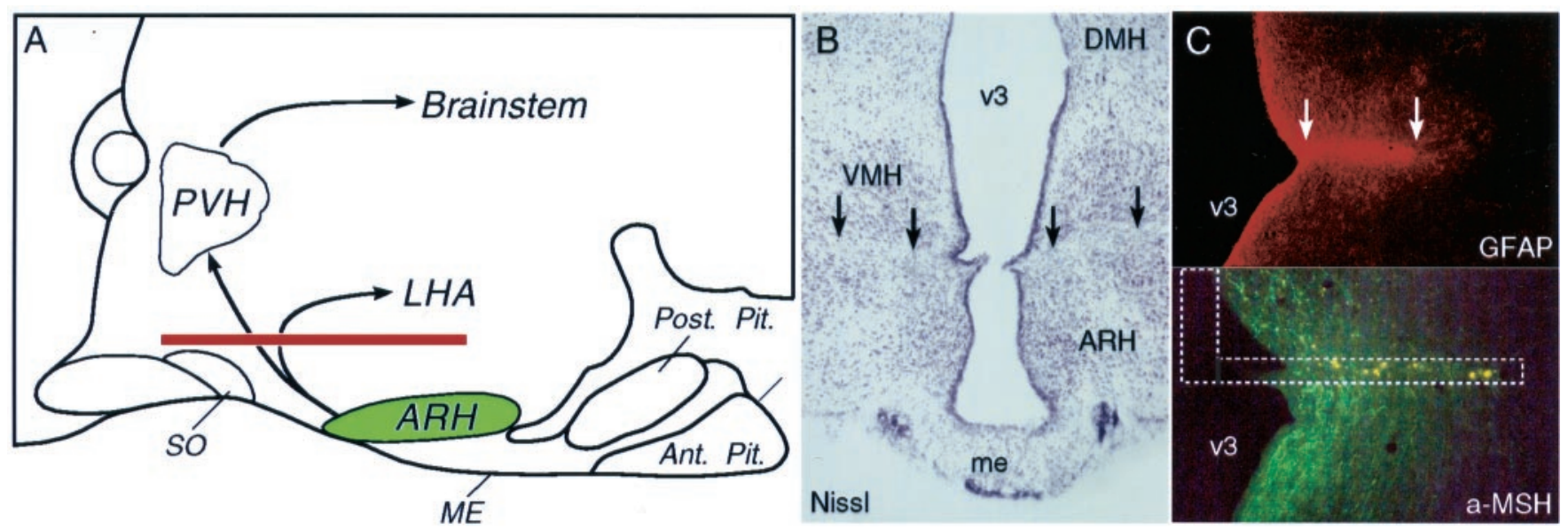

Figure 6. Evaluation of knife cuts. A, Schematic drawing of a midsagittal section through the hypothalamus to show the approximate extent and position of horizontal knife cuts (red) designed to sever the vertically directed ARH projections. Such transections are expected to compromise projections from the ARH to such feeding-related targets as the paraventricular nucleus $(P V H)$ and lateral hypothalamic area $(L H A)$. $B$, Nissl-stained section through the ARH region of a knife cut animal. Black arrows indicate placement and extent of the cut, dorsal to the ARH and roughly bisecting the ventromedial nucleus $(V M H)$. Magnification, $20 \times$. C , Immunofluorescence localization of glial fibrillary acidic protein- $(G F A P$; top $)$ and $\alpha$-MSH-IRs (bottom) reveals a glial scar at the site of the lesion (top), with significant pile-up of immunoreactive material in fibers on the side proximal to it (bottom). Dashed lines schematically indicate knife placement. Magnification, $60 \times$.

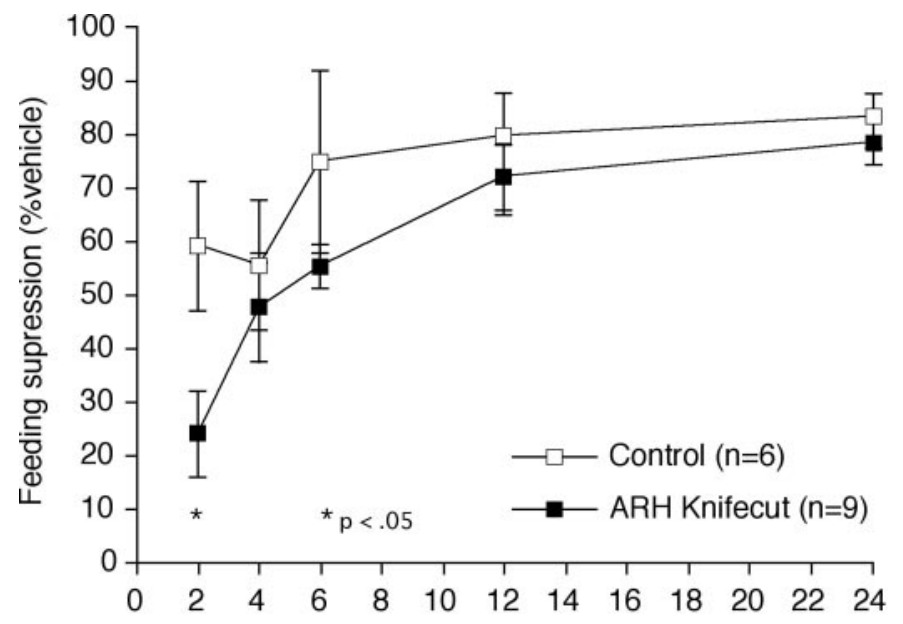

Hours Post-injection

Figure 7. Knife cut effects on IL-1-induced appetite suppression. Mean \pm SEM cumulative food intake of knife cut (filled squares) and control (open squares) rats after intravenous injection of IL-1, expressed as percentage of each animal's own response to vehicle injection. Animals bearing an ARH knife cut $(n=9)$ displayed a significantly potentiated suppression of feeding at $2 \mathrm{hr}$ after injection compared with control animals $(n=6)$. Beyond $8 \mathrm{hr}$, their food intake scores did not differ reliably from those of controls. * Differs significantly from control values, $p<0.05$.

\section{Mechanisms of cytokine-induced anorexia}

IL-1 reduces food intake at doses within the pathophysiologic range (Sonti et al., 1996a), and is recognized, along with tumor necrosis factor- $\alpha$ (Langhans and Hrupka, 1999; Bluthe et al., 2000), as a principal mediator of anorexia provoked by complex immune challenges such as endotoxin. Previous work has established that IL-1-induced feeding suppression is mediated by IL1R1 within the brain (Kent et al., 1992; Laye et al., 2000). As with other centrally driven acute phase responses, considerations of dose, route of administration, and nature of the immune challenge are critical in evaluating potential mechanisms and sites of action underlying anorexic effects. We used a moderate dose of intravenous IL-1 as a model of systemic infection, potentially allowing for the cytokine to influence ARH mechanisms by any one of a number of indirect mechanisms (see below), or by accessing directly cognate receptors in the ARH. Although the ARH lacks the fenestrated capillaries that characterize bona fide circumventricular organs, both morphological and functional evidence exists to support an ability of circulating proteins to access the ARH (van Houten et al., 1980, 1981; Shaver et al., 1992). Such a capacity for IL-1, specifically, has not been demonstrated. Alternate means of activating these neurons might involve the local release of IL-1 from vascular-associated cells (Angelov et al., 1998; Zhang et al., 2000). Similarly, prostaglandins are a prime candidate for fulfilling such a role, although their importance in sickness-related anorexia remains controversial (Shimizu et al., 1991; Shimomura et al., 1992; McCarthy, 1999; W. Wang et al., 2001). Systemic cytokines can also access the brain by way of peripheral nerves, notably the vagus (Kurosawa et al., 1997). However, as with prostaglandins, the involvement of the vagus in sickness anorexia appears to depend on the strength and nature of the immune insult, and, particularly, the route of administration. Vagal mechanisms have been most prominently implicated in central responses to agents administered into the peritoneum (Bret-Dibat et al., 1995; Laviano et al., 1995; Sergeev and Akmaev, 2000; Konsman and Dantzer, 2001).

Studies of the specific brain regions and mediators that may be involved in IL-1-induced anorexia have been limited. Support for a role of resident ARH mechanisms in sickness-associated anorexia may be found in the observation that central administration of a nonselective melanocortin $\mathrm{MC} 3 / 4$ receptor antagonist disrupts the anorexic, but not the pyrogenic, actions of both IL-1 (Lawrence and Rothwell, 2001) and LPS (Huang et al., 1999). The same treatment has recently been shown capable of overcoming cancer cachexia (Wisse et al., 2001). Interestingly, NPY or AgRP, orexigenic peptides coexpressed in arcuate neurons, can also reverse the undereating exhibited by immune challenged and/or tumor-bearing animals (Sonti et al., 1996b; Marks et al., 2001). The perspective provided by such manipulations of indi- 

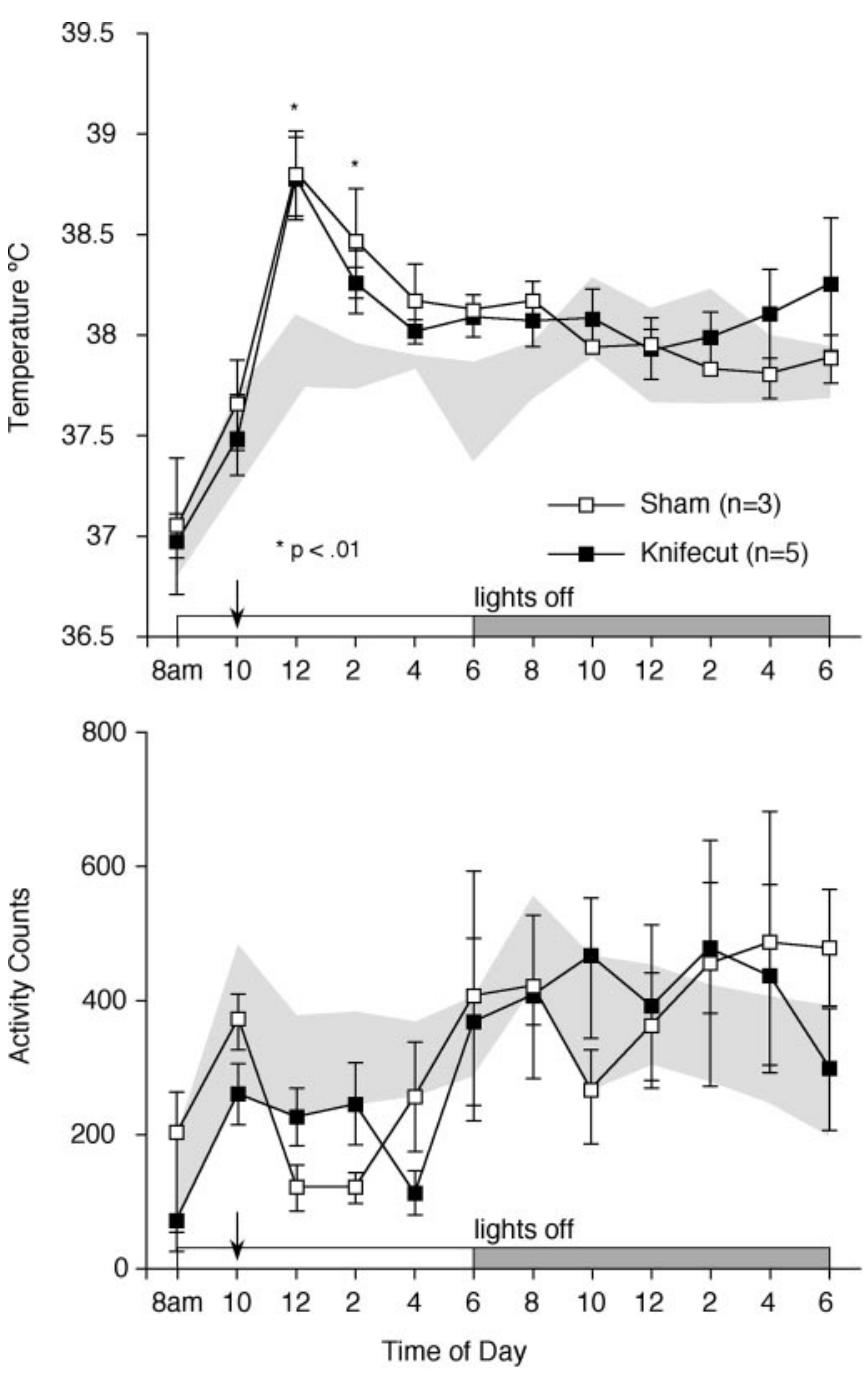

Figure 8. Temperature and activity measurements in knife cut animals. Intra-abdominally implanted telemeters were used to monitor core body temperature (top) and gross activity (bottom) in sham (open squares) and knife cut (filled squares) animals. Shaded areas represent the mean \pm 1 $\mathrm{SD}$ of pooled baseline values from sham and knife cut animals. Both groups mounted similar febrile responses to an injection of IL-1 given at 10:00 A.M. (arrow). The trends toward a mild hypoactivity exhibited by both groups after IL-1 injection were not statistically reliable. ${ }^{*}$ Differs significantly from baseline values, $p<0.01$.

vidual neurochemical systems is not easily reconciled with that deriving from our more general disruption of the arcuate nucleus or its outputs, as our manipulations affected both POMC and NPY/AgRP cells or their projections. One possible explanation for our findings of enhanced anorexia might involve lesioninduced disruption of the balance between competing actions of ligands for MC4 receptors. Although both ablations appeared to affect the intrinsic POMC and NPY/AgRP populations comparably, the sparing of the laterally disposed, extra-arcuate POMC population, which also demonstrated IL-1 sensitivity, may provide for sufficient MC4 activation to accentuate the undereating, especially under conditions of reduced antagonism by AgRP. Support for this idea may be found in the recent observation that MC4 knock-out mice are resistant to both LPS- and tumorassociated anorexia (Marks et al., 2001). Recent evidence suggests a complex interplay between intrinsic POMC and NPY systems within the arcuate nucleus (Cowley et al., 2001) and that the nature of its connections with feeding-related hypothalamic cell groups is substantially bidirectional (Horvath et al., 1999). We view our findings in this context, and as arguing against the notion that food intake or related physiologic functions can be predicted simply on the basis of the balance between the activities of resident POMC- and NPY-expressing output neurons. Teasing apart this functional circuitry will require manipulations that are both phenotypically and spatially more selective.

The circuitry and transduction mechanisms that underlie cytokine-induced anorexia remain to be identified. Candidates for such a role might include circumventricular structures like the area postrema, which expresses IL-1R1 (Ericsson et al., 1995) and has access to circuitry related to energy balance (Cunningham et al., 1994), or cells associated with the cerebral vasculature at several levels of the neuroaxis, which appear capable of engaging proximate afferent projections to the hypothalamus through the release of local signaling molecules, mainly prostaglandins (Scammell et al., 1996; Ericsson et al., 1997). Collectively, our data fail to support the hypothesized mediating role of arcuate nucleus mechanisms in IL-1-induced feeding suppression. Instead, it would appear that the net output of this cell group serves normally to limit or to antagonize this response.

\section{REFERENCES}

Abbott CR, Rossi M, Wren AM, Murphy KG, Kennedy AR, Stanley SA, Zollner AN, Morgan DGA, Morgan I, Ghatei MA, Small CJ, Bloom SR (2001) Evidence of an orexigenic role for cocaine- and amphetamine-regulated transcript after administration into discrete hypothalamic nuclei. Endocrinology 142:3457-3463.

Angelov DN, Walther M, Streppel M, Guntinas-Lichius O, van Dam A, Stennert E, Neiss WF (1998) ED2-positive perivascular phagocytes produce interleukin-1 beta during delayed neuronal loss in the facial nucleus of the rat. J Neurosci Res 54:820-827.

Baker RA, Herkenham M (1995) Arcuate nucleus neurons that project to the hypothalamic paraventricular nucleus: neuropeptidergic identity and consequences of adrenalectomy on mRNA levels in the rat. J Comp Neurol 358:518-530.

Banks W, Kastin A (1991) Blood to brain transport of interleukin links the immune and central nervous systems. Life Sci 48:PL117-PL121.

Bell ME, Bhatnagar S, Akana SF, Choi S, Dallman MF (2000) Disruption of arcuate/paraventricular nucleus connections changes body energy balance and response to acute stress. J Neurosci 20:6707-6713.

Bergen HT, Mizuno TM, Taylor J, Mobbs CV (1998) Hyperphagia and weight gain after gold-thioglucose: relation to hypothalamic neuropeptide Y and proopiomelanocortin. Endocrinology 139:4483-4488.

Blatteis CM (1992) Role of the OVLT in the febrile response to circulating pyrogens. Prog Brain Res 91:409-412.

Bluthe RM, Michaud B, Kelley KW, Dantzer R (1996) Vagotomy blocks behavioral effects of interleukin-1 injected via the intraperitoneal route but not via other systemic routes. NeuroReport 7:2823-2827.

Bluthe RM, Laye S, Michaud B, Combe C, Dantzer R, Parnet P (2000) Role of interleukin-1beta and tumour necrosis factor-alpha in lipopolysaccharide-induced sickness behaviour: a study with interleukin-1 type I receptor-deficient mice. Eur J Neurosci 12:4447-4456.

Bret-Dibat JL, Bluthe RM, Kent S, Kelley KW, Dantzer R (1995) Lipopolysaccharide and interleukin-1 depress food-motivated behavior in mice by a vagal-mediated mechanism. Brain Behav Immun 9:242-246.

Broberger C, Lecea LD, Sutcliffe JG, Hökfelt T (1998) Hypocretin/ orexin- and melanin-concentrating hormone-expressing cells form distinct populations in the rodent lateral hypothalamus: relationship to the neuropeptide $\mathrm{Y}$ and agouti gene-related protein systems. J Comp Neurol 402:460-474.

Buller K, Xu Y, Dayas C, Day T (2001) Dorsal and ventral medullary catecholamine cell groups contribute differentially to systemic interleukin-1beta-induced hypothalamic pituitary adrenal axis responses. Neuroendocrinology 73:129-138.

Chen CL, Dionne FT, Roberts JL (1983) Regulation of the proopiomelanocortin mRNA levels in rat pituitary by dopaminergic compounds. Proc Natl Acad Sci USA 80:2211-2215.

Cowley MA, Smart JL, Rubinstein M, Cerdan MG, Diano S, Horvath TL, Cone RD, MJ Low (2001) Leptin activates anorexigenic POMC neurons through a neural network in the arcuate nucleus. Nature 411: 480-484.

Cunningham Jr ET, Miselis RR, Sawchenko PE (1994) The relationship of efferent projections from the area postrema to vagal motor and 
brainstem catecholamine-containing cell groups: an axonal transport and immunohistochemical study in the rat. Neuroscience 58:635-648.

Dantzer R (2001) Cytokine-induced sickness behavior: where do we stand? Brain Behav Immun 15:7-24.

Elias CF, Lee C, Kelly J, Aschkenasi C, Ahima RS, Couceyro PR, Kuhar MJ, Saper CB, Elmquist JK (1998a) Leptin activates hypothalamic CART neurons projecting to the spinal cord. Neuron 21:1375-1385.

Elias CF Saper CB, Maratos-Flier E, Tritos NA, Lee C, Kelly J, Tatro JB, Hoffman GE, Ollmann MM, Barsh GS, Sakurai T, Yanagisawa M, Elmquist JK (1998b) Chemically defined projections linking the mediobasal hypothalamus and the lateral hypothalamic area. J Comp Neurol 402:442-459.

Elmquist JK, Elias CF, Saper CB (1999) From Lesions to Leptin: Hypothalamic control of food intake and body weight. Neuron 22:221-232.

Ericsson A, Kovacs KJ, Sawchenko PE (1994) A functional anatomical analysis of central pathways subserving the effects of interleukin-1 on stress-related neuroendocrine neurons. J Neurosci 14:897-913.

Ericsson A, Liu C, Hart RP, Sawchenko PE (1995) Type I interleukin-1 receptor in the rat brain: distribution, regulation, and relationship to sites of IL-1-induced cellular activation. J Comp Neurol 361:681-698.

Ericsson A, Arias C, Sawchenko PE (1997) Evidence for an intramedullary prostaglandin-dependent mechanism in the activation of stressrelated neuroendocrine circuitry by intravenous interleukin-1. J Neurosci 17:7166-7179

Hart BL (1988) Biological basis of the behavior of sick animals. Neurosci Biobehav Rev 12:123-137.

Hart BL (1990) Behavioral adaptations to pathogens and parasites: five strategies. Neurosci Biobehav Rev 14:273-294.

Herkenham M, Lee HY, Baker RA (1998) Temporal and spatial patterns of c-fos mRNA induced by intravenous interleukin-1: a cascade of non-neuronal cellular activation at the blood-brain barrier. J Comp Neurol 400:175-196.

Horvath TL, Diano S, van den Pol AN (1999) Synaptic interaction between hypocretin (orexin) and neuropeptide $\mathrm{Y}$ cells in the rodent and primate hypothalamus: a novel circuit implicated in metabolic and endocrine regulations. J Neurosci 19:1072-1087.

Huang Q-H, Hruby VJ, Tatro JB (1999) Role of central melanocortins in endotoxin-induced anorexia. Am J Physiol 276:R864-R871.

Kalra SP, Dube MG, Pu S, Xu B, Horvath TL, Kalra PS (1999) Interacting appetite-regulating pathways in the hypothalamic regulation of body weight. Endocr Rev 20:68-100.

Kent S, Bluthe R, Dantzer R, Hardwick A, Kelley K, Rothwell N, Vannice J (1992) Different receptor mechanisms mediate the pyrogenic and behavioral effects of interleukin 1. Proc Natl Acad Sci USA 89:9117-9120.

Kent S, Bret-Dibat J, Kelley KW, Dantzer R (1996) Mechanisms of sickness-induced decreases in food-motivated behavior. Neurosci Biobehav Rev 20:171-175.

Khachaturian H, Akil H, Brownstein MJ, Olney JW, Voigt KH, Watson SJ (1986) Further characterization of the extra-arcuate alphamelanocyte stimulating hormone-like material in hypothalamus: biochemical and anatomical studies. Neuropeptides 7:291-313.

Konsman JP, Dantzer R (2001) How the immune and nervous systems interact during disease-associated anorexia. Nutrition 17:664-668.

Kurosawa M, Uvnas-Moberg K, Miyasaka K, Lundeberg T (1997) Interleukin-1 increases activity of the gastric vagal afferent nerve partly via stimulation of type A CCK receptor in anesthetized rats. J Auton Nerv Syst 62:72-78.

Langhans W, Hrupka B (1999) Interleukins and tumor necrosis factor as inhibitors of food intake. Neuropeptides 33:415-424.

Larhammar D, Ericsson A, Persson H (1987) Structure and expression of the rat neuropeptide Y gene. Proc Natl Acad Sci USA 84:2068-2072.

Laviano A, Yang ZJ, Meguid MM, Koseki M, Beverly JL (1995) Hepatic vagus does not mediate IL-1 alpha induced anorexia. NeuroReport 6:1394-1396.

Lawrence CB, Rothwell NJ (2001) Anorexic but not pyrogenic actions of interleukin-1 are modulated by central melanocortin-3/4 receptors in the rat. J Neuroendocrinol 13:490-495.

Laye S, Gheusi G, Cremona S, Combe C, Kelley K, Dantzer R, Parnet P (2000) Endogenous brain IL-1 mediates LPS-induced anorexia and hypothalamic cytokine expression. Am J Physiol 279:R93-R98.

Majde JA (1993) Microbial cell-wall contaminants in peptides: a potential source of physiological artifacts. Peptides 14:629-632.

Marks DL, Ling M, Cone RD (2001) Role of the central melanocortin system in cachexia. Cancer Res 61:1432-1438.

Martin SM, Malkinson TJ, Veale WL, Pittman QJ (1990) Depletion of brain alpha-MSH alters prostaglandin and interleukin fever in rats. Brain Res 526:351-354.

McCarthy DO (1999) Inhibitors of prostaglandin synthesis do not im- prove food intake or body weight of tumor-bearing rats. Res Nurs Health 22:380-387.

Meister B, Ceccatelli S, Hökfelt T, Andén N-E, Andén M, Theodorsson E (1989) Neurotransmitters, neuropeptides and binding sites in the rat mediobasal hypothalamus: effects of monosodium glutamate (MSG) lesions. Exp Brain Res 76:343-368.

Nemeroff CB, Grant LD, Bissette G, Ervin GN, Harrell LE, Prange AJ (1977) Growth, endocrinological and behavioral deficits after monosodium L-glutamate in the neonatal rat: possible involvement of arcuate dopamine neuron damage. Psychoneuroendocrinology 2:179-196.

Opp MR, Obal F Jr, Payne L, Krueger JM (1990) Responsiveness of rats to interleukin-1: effects of monosodium glutamate treatment of neonates. Physiol Behav 48:451-457.

Plata-Salaman CR, Vasselli JR, Sonti G (1997) Differential responsiveness of obese (fa/fa) and lean $(\mathrm{Fa} / \mathrm{Fa})$ Zucker rats to cytokine-induced anorexia. Obes Res 5:36-42.

Plata-Salaman CR, Peloso E, Satinoff E (1998) Cytokine-induced fever in obese $(\mathrm{fa} / \mathrm{fa})$ and lean $(\mathrm{Fa} / \mathrm{Fa})$ Zucker rats. Am J Physiol 275:R1353-1357.

Reyes TM, Sawchenko PE (2000) Is the arcuate nucleus involved in cytokine-induced anorexia. Soc Neurosci Abstr 26:1179.

Sawchenko PE (1998) Toward a new neurobiology of energy balance, appetite, and obesity: the anatomists weigh in. J Comp Neurol 402:435-441.

Sawchenko PE, Li HY, Ericsson A (2000) Circuits and mechanisms governing hypothalamic responses to stress: a tale of two paradigms. Prog Brain Res 122:61-78.

Scammell TE, Elmquist JK, Griffin JD, Saper CB (1996) Ventromedial preoptic prostaglandin E2 activates fever-producing autonomic pathways. J Neurosci 16:6246-6254.

Sergeev VG, Akmaev IG (2000) Effects of vagotomy and bacterial lipopolysaccharide on food intake and expression of cyclooxygenase-2 mRNA in rat brain vessels. Bull Exp Biol Med 129:553-555.

Shaver SW, Pang JJ, Wainman DS, Wall KM, Gross PM (1992) Morphology and function of capillary networks in subregions of the rat tuber cinereum. Cell Tissue Res 267:437-448.

Shimizu H, Uehara Y, Shimomura Y, Kobayahi I (1991) Central administration of ibuprofen failed to block the anorexia induced by nterleukin-1. Eur J Pharmacol 195:281-284.

Shimomura Y, Inukai T, Kuwabara S, Shimizu H, Takahashi M, Sato N Uehara Y, Tanaka Y, Kobayashi I (1992) Both cyclooxygenase and lipoxygenase inhibitor partially restore the anorexia by interleukin-1 beta. Life Sci 51:1419-1426.

Smith J, Urba W, Steis R, Janik J, Fenton B, Sharfman W, Conlon K Sznol M, Creekmore S, Wells N, Elwood L, Keller J, Hestdal K, Ewel C, Rossio J, Koop W, Shimuzu M, Oppenheim J, Longo D (1990) A phase I trial of interleukin-1 alpha (IL-1 alpha) alone and in combination with indomethacin. Lymphokine Res 9:568.

Sonti G, Ilyin SE, Plata-Salaman CR (1996a) Anorexia induced by cytokine interactions at pathophysiological concentrations. Am J Physiol 270:R1394-R1402.

Sonti G, Ilyin SE, Plata-Salaman CR (1996b) Neuropeptide Y blocks and reverses interleukin-1 beta-induced anorexia in rats. Peptides 17:517-520

Van Dam AM, De Vries HE, Kuiper J, Zijlstra FJ, De Boer AG, Tilders FJH, Berkenbosch F (1996) Interleukin-1 receptors on rat brain endothelial cells: a role in neuroimmune interaction? FASEB J 10:351-356.

van Houten M, Posner BI, Kopriwa B, Brawer JR (1980) Insulin binding sites localized to nerve terminals in rat median eminence and arcuate nucleus. Science 207:1081-1083.

van Houten M, Khan MN, Khan RJ, Posner BI (1981) Blood-borne adrenocorticotropin binds specifically to the median eminence arcuate region of the rat hypothalamus. Endocrinology 108:2385-2387.

Wang C, Mullet MA, Glass MJ, Billington CJ, Levine AS, Kotz CM (2001) Feeding inhibition by urocortin in the rat hypothalamic paraventricular nucleus. Am J Physiol 280:R473-480.

Wang W, Lonnroth C, Svanberg E, Lundholm K (2001) Cytokine and cyclooxygenase- 2 protein in brain areas of tumor-bearing mice with prostanoid-related anorexia. Cancer Res 61:4707-4715.

Watkins LR, Maier SF, Goehler LE (1995) Cytokine-to-brain communication: A review and analysis of alternative mechanisms. Life Sci 57:1011-1026.

Wisse BE, Frayo RS, Schwartz MW, Cummings DE (2001) Reversal of cancer anorexia by blockade of central melanocortin receptors in rats. Endocrinology 142:3292-3301.

Zhang W, Smith C, Howlett C, Stanimirovic D (2000) Inflammatory activation of human brain endothelial cells by hypoxic astrocytes in vitro is mediated by IL-1beta. J Cereb Blood Flow Metab 20:967-978. 